\title{
Formação humana e Educação Física: proposições para além do conservadorismo
}

Alisson Slider do Nascimento de Paula ${ }^{1}$ André Luis Façanha da Silva², Kátia Regina Rodrigues Lima $^{3}$

\begin{abstract}
Resumo
Neste artigo, abordamos a educação e a Educação Física como processo de realização de uma comunidade sobre o desenvolvimento do homem, a fim de que ele possa atuar em uma sociedade conscientizada para aceitação dos objetivos coletivos. Assim, pensando a educação em uma perspectiva ontológica, a Educação Física pode ser um veículo para a formação do ser, por se tratar de um componente curricular da educação básica brasileira. Como tal, deve propiciar uma contribuição na formação integral dos educandos e na formação do homem, no que diz respeito à formação do sujeito crítico e autônomo. Para isso, com base na perspectiva crítico-superadora, iremos materializar proposições que visem à formação do homem a partir do caráter sociológico, filosófico e antropológico.
\end{abstract}

\section{Palavras-chave}

Formação Humana. Educação Física. Currículo. Formação de Professores. Perspectiva Crítico-Superadora.

1. Graduando em Educação Física pela Universidade Estadual Vale do Acaraú, membro do Grupo de Estudos e Pesquisas em Trabalho, História, Educação e Desenvolvimento (GETHED) e do Grupo de Estudos Marxistas (GEM).E-mail: alisson.slider@yahoo.com.

2. Mestrando em Saúde da Família pela Universidade Federal do Ceará, membro da Coordenação Colegiada do Projeto "Vigilância e prevenção das doenças e agravos não transmissíveis para o fortalecimento da política de promoção da saúde do município de Sobral-CE". E-mail: andrefacanhaef@gmail.com.

3. Doutora em Educação pela Universidade Federal de São Carlos, professora na Universidade Estadual Vale do Acaraú, membro do Grupo de Estudos e Pesquisas em Trabalho, História, Educação e Desenvolvimento (GETHED). E-mail: kareli20042004@yahoo.com.br. 


\title{
Human formation and Physical Education: proposals for beyond
} the conservatism

Alisson Slider do Nascimento de Paula*, André Luis Façanha da Silva**, Kátia Regina Rodrigues Lima***

\begin{abstract}
In this work, we focus the education and Physical Education as a process of implementing a community on the development of man in order that he can act in a society smartening for acceptance of collective goals. With this, thinking education within an ontological perspective, Physical Education can be a vehicle for training be for treating a curricular component of the brazilian basic education should provide a contribution to the integral formation of the students, as well as in the human being formation, concerning the formation of the critical and autonomous. For this, based on perspectivecritical surpassing, we will materialize propositions that seek from the sociological, philosophical, anthropological formation of man.
\end{abstract}

\section{Keywords}

Human Formation. Physical Education. Curriculum. Teacher Training. Critical-Superador Perspective.

* Graduating student in Physical Education at the State University Vale do Acaraú, member of Research Group Educational in Work, History, Education and Developmen (GETHED) and Marxist Study Group (GEM). E-mail: alisson.slider@yahoo.com.

** Candidate for a master's degree in Family Health at the Federal University of Ceará, member of Collegiate Coordenation of the Project: "Vigilância e prevenção das doenças e agravos não transmissíveis para o fortalecimento da política de promoção da saúde do município de Sobral-CE". E-mail: andrefacanhaef@gmail. com.

*** Doctor in Education at the Federal University of São Carlos, professor at the State University Vale do Acaraú, member of Research Group Educational in Work, History, Education and Developmen (GETHED). E-mail: kareli20042004@yahoo.com.br. 


\section{Introdução}

Nos últimos anos, a pesquisa em educação e Educação Física vem passando por uma transição, a qual se aloca no período pós-moderno, sendo este o movimento que representa um conjunto variado de perspectivas, abrangendo uma diversidade de campos intelectuais, políticos, estéticos e epistemológicos. Todavia, esse movimento desconsidera o materialismo histórico. Para a esquerda pósmoderna, o marxismo reprime o homem a uma visão monolítica socioeconômica; sua identidade não crê nas múltiplas identidades e suas essências econômicas não percebem a construção discursiva da realidade (TAFFAREL; SANTOS JÚNIOR, 2010).

Por meio dessas concepções, encontramos embates na Educação Física no contexto da Educação Básica e Superior. Identifica-se um conflito no qual se pode considerar a falta de legitimidade do conhecimento a ser tratado na escola. Nesse sentido, urge a necessidade de problematizarmos alguns aspectos como: Qual o modelo de sociedade que buscamos por meio da escola? Qual o perfil de professor para a formação do aluno enquanto ser sóciohistórico? Quais as relações do currículo face à transformação social por meio da escola? Qual a contribuição da Educação Física enquanto disciplina curricular frente aos problemas sociais de classe? O que é prioritário nas aulas, a cultura hegemônica ou a valorização da cultura da classe trabalhadora, em suas múltiplas singularidades tanto individual como coletiva?

Pode-se considerar consensual a definição de educação como formação humana. A questão, portanto, que necessita ser examinada é: em que consiste a formação humana? Compreende-se que alguns homens, crianças e jovens são formados por outros homens, "o adulto". Contudo, para pensarmos em formação humana, devemos pensar no "ser" livre. Apenas assim, o homem, a partir de suas decisões próprias, seria capaz de intervir pessoalmente na situação para aceitar, rejeitar ou transformar. Enquanto ser livre, ele se mostraria capaz de optar e tomar decisões. Esse aspecto já permitiria responder positivamente à questão da possibilidade da educação e da formação humana (SAVIANI; DUARTE, 2012).

Sendo assim, nesse trabalho, iremos abordar a educação no sentido mais amplo, como processo de execução de uma comunidade sobre o desenvolvimento do homem, a fim de que ele possa atuar em uma sociedade conscientizada para aceitação dos objetivos coletivos. Para tal educação, deve-se refletir o ser no plano intelectual consciente e físico das possibilidades e limitações, sendo capaz de apreender, refletir, criticar a realidade do mundo, devendo ponderar seu papel de transformação social como uma sociedade que supere as mazelas do capitalismo no atual modelo de sociedade.

Com isso, pensando a educação em uma perspectiva ontológica, a Educação Física pode ser um veículo para a formação do ser. Por se tratar de um componente curricular da educação básica brasileira, deve propiciar uma contribuição na formação integral dos educandos, bem como na formação do homem, no que diz respeito à formação do ser crítico e autônomo. Por meio da perspectiva críticosuperadora, iremos materializar proposições que busquem, a partir do caráter sociológico, filosófico, antropológico a formação do homem.

Assim, para que possamos compreender os embates e problemáticas que proliferam uma educação conservadora/idealista, trataremos, primeiramente, da formação de professores. Em seguida, falaremos sobre a formação de intelectuais orgânicos que poderão estar designados para conservar ou superar, além de embates que alienam a formação profissional do professor de Educação Física e seu campo de atuação. Por conseguinte, trataremos do papel 
da educação na luta de classes, um espectro que, para Marx e Engels (2007), está no seio histórico da sociedade.

Em continuidade, abordaremos o currículo como sendo o meio que irá definir, a partir de seus eixos e objetivos, qual o modelo de homem que se pretende formar para atuar na sociedade. Mais à frente, iremos diagnosticar as possibilidades da formação humana por meio da perspectiva crítico-superadora e disseminar reflexões críticas e autônomas dos educandos acerca da realidade social, para que, assim, possam atuar a ponto de buscar transformação e superação do modo de produção capitalista.

Por fim, buscaremos materializar procedimentos pedagógicos que possam nortear o exercício da prática educativa, no que diz respeito à transmissão do acervo cultural historicamente acumulado pela humanidade, em especial a cultura corporal.

\section{Os desafios e confrontos na formação de professores de Educação Física}

A formação de professores no Brasil, em seu contexto histórico, encontra um caminho estreito, longo e com problemas, no que tange às precariedades das políticas formativas, das quais sucessivas alternâncias não conseguiram estabelecer um parâmetro minimamente constituído de disposição docente para fazer frente aos problemas afrontados pela educação escolar do país.

Neste contexto, conforme Saviani (2009), dois modelos de formação de professores são concebidos:

a) modelo dos conteúdos culturais-cognitivos: para este modelo a formação dos professores se esgota na cultura geral e no domínio específico dos conteúdos da área de conhecimento correspondente à disciplina que o professor irá lecionar. b) modelo pedagógico-didático: Contrapondo-se ao anterior, este modelo considera que a formação propriamente dita dos professores só se completa com o efetivo preparo pedagógico-didático. (SAVIANI, 2009, p. 147-148, grifos do autor).

Assim, a questão da formação docente é permeada por diversos dilemas. Nesta ocasião, todavia, será abordado somente aquele referente aos modelos expostos sobre formação de professores. O dilema manifesta-se de modo imediato: compreende-se que as duas dimensões - os conteúdos culturais-cognitivos e os procedimentos didático-pedagógicos devam integrar o processo de formação de professores. Como, entretanto, articulá-los apropriadamente? (SAVIANI, 2009).

A partir desta problemática, conceitua-se que:

[...] o dilema resultou da dissociação de aspectos indissociáveis do ato docente, logicamente a saída do dilema implica a recuperação da referida indissociabilidade. (SAVIANI, 2009, p. 151).

E, ainda,

Uma vez que a dissociação se deu por um processo de abstração, para recuperar a indissociabilidade será necessário considerar o ato docente como fenômeno concreto, isto é, tal como ele se dá efetivamente no interior das escolas. Um caminho prático e objetivo para verificar a montagem e o modo de operar dos currículos escolares é partir dos livros didáticos, o que permitiria tomá-los como ponto de partida para a reformulação dos cursos de Pedagogia e dos demais cursos de licenciatura. (SAVIANI, 2009, p. 151).

Esses dilemas estão presentes em todas as licenciaturas e currículos escolares brasileiros. A busca por um modelo de formação de professor contribui para reflexões acerca das reformulações curriculares das licenciaturas, tornando-se significativo para o debate do curso de Educação Física.

Os cursos de Educação Física, no Brasil, 
encontram-se, também, em meio a embates em seu projeto histórico, bem como lutas para reformulações das atuais Diretrizes Curriculares Nacionais (DCN), propostas pelo Conselho Nacional de Educação (CNE), que determinam as possibilidades de atuação do professor da área. Todavia, diante dos problemas e confrontos, este campo do conhecimento encontra-se em estado de expansão nas escolas de formação de professores, no que diz respeito a novos cursos em novas universidades e faculdades, públicas e privadas.

A formação dos professores de Educação Física no Brasil situa-se no contexto da formação universitária, em especial na de licenciandos. Atualmente, por força das Resoluções 01/02, 02/02 e 7/04 do CNE, está dividida em formação nos cursos de Licenciatura e de Graduação em Educação Física. Um balanço preliminar sobre a situação da Educação Física no Brasil, considerando os cursos de Licenciatura e Graduação, permite-nos afirmar que são ao todo 466 cursos habilitados, 81 no Nordeste e 19 na Bahia. Esses cursos formam na Bahia, aproximadamente, 330 profissionais por ano. No Nordeste são 2.430 e no Brasil, 13.980. Ao todo, são 17 cursos de Pós-Graduação em instituições públicas que integrem ensino-pesquisa-extensão, Graduação e PósGraduação, universidade-sociedade, Ensino Superior e Educação Básica, Universidades e Movimentos de Luta Social no Nordeste do Brasil. (TAFFAREL et al., 2007, p. 41).

Nesse sentido, grande massa de professores de Educação Física está sendo formada anualmente e entrando em mecanismos de concorrência-seletiva. Alguns, por afirmação e estabilidade, a partir de sua força de trabalho. Outros, por decisão de seguir a formação continuada.

Muito embora alguns desses pontos ilustrem aspectos positivos, a Educação Física apresenta problemas de diferentes origens, sendo eles: teóricos, epistemológicos, financeiros, estruturais, curriculares e políticos (TAFFAREL et al., 2007). Com isso, é necessário analisar seu projeto histórico, bem como os processos advindos dos sistemas, os quais penetram nas universidades, desmantelando a autonomia universitária ${ }^{4}$. Podemos citar, portanto, uma adequação da Educação Básica e da Educação Superior às políticas imperialistas ${ }^{5}$. Deste modo, para Mèszáros (2008), as consequências dessas adequações são nefastas.

A partir dos embates frente aos sistemas CONFEF/CREF e às atuais DCN, a Educação Física encontra-se em face da legitimação do campo de atuação profissional. Assim sendo, a fragmentação do currículo da área e a priorização de conteúdos biológicos (Bacharelado) e pedagógicos (Licenciatura), por conseguinte, propiciam uma formação alienada aos estudantes da área. As políticas imperialistas recorrem a esses sistemas como estratégia do capital para manter sua hegemonia, que não é outra coisa senão uma tática de perpetuação e opressão nos campos do trabalho

4. O que gera a perda da autonomia universitária é a interferência dos poderes legislativo e executivo nas universidades e faculdades, mediante medidas legais que vão desde a elucidação de diretrizes até questões de orçamento para a educação superior, contratação de pessoal, programas e projetos que despertem interesses ao governo, e, por outro lado, a pressão exercida pelas empresas, Conselhos - como o Conselho Federal de Educação Física (CONFEF) - em sua ação corporativa e autoritária sobre o trabalho pedagógico, bem como outros mecanismos que constituem e defendem os interesses do capital e sua premência de subordinar a formação de professores ao projeto de mundialização do capital. A tudo isso soma-se a escassez de uma política articulada nacionalmente, por um pacto federativo, entre a Federação, os Estados e os municípios para o enfrentamento das questões voltadas à educação, Educação Física, esporte e lazer na cidade e no campo. (TAFFAREL, 2007).

5. Citamos aqui a implementação de reformas no aparelho do Estado e enquanto sistema educacional - LDB 9.393/96, PCN's, Novas Diretrizes Curriculares para os cursos de graduação, reforma universitária, que não contemplam as reivindicações da comunidade universitária, e isso tem gerado resistências por parte das organizações sindicais. 
impossibilitando a emancipação humana, no que tange em conceber uma realidade de trabalho. Este, por sua vez, está adequado aos moldes da exploração do homem pelo homem, visando lucros de quem gere determinada ação do trabalho. Isto é concernente a uma visão mercadológica do modo de produção capitalista. Para Taffarel et al. (2006, p. 94),

a regulamentação da profissão e o sistema CREF/CONFEF são mediadores entre as necessidades mais gerais da lógica capitalista e o trabalho do professor.

Nesse sentido, portanto, a formação de professores de Educação Física, sob essa mediação da lógica capitalista e o trabalho docente, proporciona um campo de trabalho alienante. Para consolidar este ensejo conta, ainda, com contribuições significativas da ingerência do Estado e a integração ao mercado.

A hodierna fase de desenvolvimento do modo de produção capitalista, determinada em torno de disposições e indisposições no processo de acumulação do capital, das alterações na base técnica das forças produtivas, da ascensão e estabilidade do neoliberalismo, da precarização do trabalho, dentre outros, reflete de modo determinante acerca dos processos de formação humana, subalternando-os às suas demandas (TAFFAREL; SANTOS JÚNIOR, 2010).

No alusivo às ordens de formação humana, a "nova" condição impõe a formação de trabalhadores competentes ao trabalho abstrato e submetidos ao capital (SILVA JÚNIOR, 2005; MÉSZÁROS, 2008). Trata-se, portanto, de assegurar trabalhadores hábeis de acordo com o nível de conhecimento técnico aplicado no processo produtivo e, simultaneamente, assegurar que cada indivíduo "adote como suas próprias às metas de reprodução objetivamente possíveis do sistema" (MÉSZÁROS, 2008, p. 44).
Sendo assim, parece-nos que, por meio da fragmentação da formação de professores de Educação Física; da limitação dos campos de atuação a partir de sua formação classificando em formal e não formal; da opressão advinda dos sistemas CONFEF/CREF; as políticas formativas estão contribuindo, desse modo, para a formação de professores que, quando inseridos no seu campo de trabalho, em especial a escola, estão ali para apenas reproduzirem a partir de um determinado conhecimento técnico por intermédio de um trabalho não material ${ }^{6}$, assegurar a reprodução social, no que diz respeito à preservação da hegemonia burguesa.

Na perspectiva do trabalho "não material" do professor, a partir da atual formação defendida pelas DCN acerca da formação em Educação Física, no que tange à educação escolar, o atual modelo de formação utiliza o primeiro modelo mencionado anteriormente - o dos conteúdos culturais-cognitivos -, partindo de um ensino sem uma reflexão acerca da realidade social dos alunos, tampouco sem uma organização didático-pedagógica em relação à sistematização dos conhecimentos científicos construídos historicamente pelo homem, que no âmbito da Educação Física refere-se à Cultura Corporal. Deste modo, este processo estaria apenas contribuindo para uma formação escolar em que os conhecimentos tratados não correspondem à realidade social, perdendo a legitimidade na vida de cada aluno, levando-os para a reprodução das relações de produção de tipo capitalista. Para isso, essa formação toma a si todas as crianças de todas as classes sociais e inculca-lhes, durante anos a fio, de audiência obrigatória "saberes práticos" envolvidos na ideologia dominante (ALTHUSSER, 1985).

Por fim, é premente que manifestações advindas dos sujeitos integrantes da universidade intervenham para melhorias nesse campo de

6. Saviani (1997) distingue o trabalho material do trabalho não material: enquanto o primeiro alude ao processo de produção de bens materiais indispensáveis à existência humana, o segundo, que se relaciona ao conhecimento das propriedades do mundo real (ciência), de valorização (ética) e de simbolização (arte), concebe o instrumento que oportuniza preceder em ideias a ação do trabalho material. 
problemáticas. Estudantes de Educação Física, por meio do Movimento Estudantil de Educação Física (MEEF); integrantes da Executiva Nacional dos Estudantes de Educação Física (EXNEEF); professores; sindicatos dos professores de Educação Física devem levantar a bandeira por uma formação de qualidade, democrática, sem interferências de conselhos interessados em explorar os trabalhadores da área. Que essa vanguarda lute para uma formação que, no campo escolar, possa contribuir para a reflexão crítica e autônoma do estudante, bem como sua formação integral; e que o campo não formal atinja os objetivos com qualidade, deixando de lado a visão mercadológica da profissão.

\section{Educação e o espectro da luta de classes}

Em uma sociedade dividida em classes com interesses antagônicos, identificamos situações de trabalho de caráter "explorador", imposta pela classe hegemônica (burguesia) sobre a classe subalterna (proletariado). Isto ilustra toda a história da humanidade (MARX; ENGELS, 2007), no que tange à disputa por concretizar objetivos de uma classe que busca meios que possam constituir uma sociedade socialista "sem classes" e que procura apenas a manutenção do status quo e elementos que engrandeçam, cada vez mais, suas fontes de riquezas, por meio da exploração do trabalho humano.

Do ponto de vista advindo do trabalho, necessita-se buscar em seu projeto histórico o problema: quando, afinal, o homem esteve livre?7 $\mathrm{Na}$ história da humanidade, passamos por épocas que ilustram, em grande expressão, a exploração do homem pelo homem. Tivemos a sociedade escravagista ${ }^{8}$, por conseguinte, a sociedade feudal $^{9}$ e, por fim, a sociedade capitalista, na qual a ciência contribuiu para a construção de máquinas e o homem - operário - é livre, podendo atuar onde entender que seja melhor para si. Todavia, já não possui propriedades e tampouco espera do mercado o acolhimento sobre suas decisões acerca de onde e quando irá trabalhar. Ou seja, o homem é livre juridicamente, entretanto está preso às amarras que não o possibilita chegar ao nível de igualdade em relação à burguesia.

Nesse modelo de sociedade, o operário é sobrecarregado a partir da intensificação e precarização do trabalho que exerce nas fábricas/indústrias, visando o salário. Este salário, identificamos como sendo apenas a fonte de sua sobrevivência. Em verdade, o operário produz mercadorias em alta escala, todavia o capital gerado a partir da venda dessas mercadorias é dividido: grande parte vai para a manutenção e compras de mais máquinas - capital constante-, determinada parte será o lucro para o capitalista, e o valor mínimo, apenas o necessário para sobreviver, será o salário do operário - capital variável. Com isso, surge a necessidade da atenção maior do homem e da concorrência para o operário não perder seu emprego para mão de obra mais barata, o que causa a alienação advinda desse processo exploratório. Nessa ação, o homem não encontra força para se rebelar coletivamente contra o sistema opressor capitalista, uma vez que falta sistematização crítica, política e teórica na vanguarda (LÊNIN, 2011). Sendo assim, com a necessidade do

7. Esta indagação está vinculada com a reflexão do homem poder agir a partir de suas escolhas, poder selecionar o que quiser e quando quiser, sem que haja ninguém para impor ordem.

8. O escravo trabalhava para o senhor. Produzia no campo, nas minas, nas oficinas. O próprio escravo era propriedade do senhor, que lhe dava o sustento, ficando com o produto de seu trabalho. Toda a sociedade vivia então à custa desse trabalho escravo, estava organizada à base desse trabalho e possuía toda uma série de leis que sancionavam e regulavam essa forma particular de exploração.

9. O principal objeto de exploração era o camponês. Chamado de servo da gleba, esse camponês estava preso a um pedaço de terra, sendo obrigado a dar uma parte de sua colheita ao senhor feudal e, sem retribuição, trabalhar determinado número de dias nas terras do senhor. 
trabalho para sustentar a família e a si próprio, os operários incentivam desde cedo seus filhos a ingressarem nessa rede, causando alienação ainda cedo, impelindo os filhos a começarem a trabalhar precocemente, impedindoos, por sua vez, de concluírem os estudos.

A partir disso, como intervir para superar esse processo alienante de exploração do homem pelo homem? Qual o projeto de sociedade capaz de guiar a luta de classes, a ponto de existir uma sociedade igualitária "sem classes"? Em que a educação pode contribuir nesse processo de superação? A Educação Física teria algo a contribuir na luta pela transformação da sociedade, bem como na formação humana?

Acreditamos que estes questionamentos sejam pertinentes ao problema central, no que diz respeito à formação humana. Para pensarmos primeiramente na configuração da sociedade de classes, temos que levar em consideração a alienação do homem pelo trabalho e também sua trajetória escolar. Isso nos leva a refletir qual a função social da escola? Mészáros (2008) considera que a educação deve qualificar para a vida e não para o mercado. A crise educacional não resulta somente da transição política dos processos educacionais, mas, sim, da translação da estrutura dos valores que intensificam a ideologia da sociedade capitalista.

Saviani (1997; 2008) atribui à escola a tarefa de promover o homem e, nessa perspectiva, propõe melhorias profundas na formação docente e no ensino discente. Para tanto, desenvolveu uma concepção de educação para as escolas brasileiras, na qual a apropriação do conhecimento historicamente acumulado é o ápice. A educação é um fenômeno característico do ser humano (SAVIANI, 1997), razão pela qual entender sua essência demanda, antes de tudo, a compreensão da própria essência humana.

Consoante Mészáros (2008), a função educacional é concomitantemente à de uma transformação social plena e emancipadora. Elas são inerentes. A transformação social integral é inconcebível, sem uma real e ativa cooperação da educação no seu sentido amplo. O opoente também é axiomático: a educação não pode ter êxito suspensa no ar, podendo e devendo ser vinculada dialeticamente com as circunstâncias modificáveis e as instâncias da transformação social emancipadora e progressiva em curso.

\section{Proposições para um currículo crítico}

Quando nos deparamos com as diversas problemáticas frente ao projeto histórico, buscamos possibilidades de superação de determinadas dificuldades. Entretanto, quando observamos os mesmos problemas sendo realizados em processo contínuo, todavia camuflados por toda uma política educacional reacionária, submissa aos interesses hegemônicos da sociedade, recorremos a toda uma análise histórica, no que diz respeito à essência da problemática. Assim, buscamos elementos significativos, evidentes e teleológicos que superem todas as mazelas que insistem em fragmentar a sociedade, beneficiando apenas um lado, no que diz respeito a uma unilateralidade acabada.

Apesar dos trabalhos de Saviani (2008; 2010) diagnosticarem as teorias educacionais que foram utilizadas com suas essências idealistas, positivistas, que anulavam os cidadãos, teorias com objetivos similares atuam na contemporaneidade nas redes educacionais. Para tanto, acreditamos na forte influência do currículo na escola. Sendo assim,

[...] o currículo é também uma questão de poder e que as teorias do currículo, na medida em que buscam dizer o que o currículo deve ser, não podem deixar de estar envolvidas em questões de poder. Selecionar é uma operação de poder. Privilegiar um tipo de conhecimento é uma operação de poder. Destacar, entre as múltiplas possibilidades, uma identidade ou subjetividade como sendo ideal é uma operação de poder. (SILVA, 1999, p. 16). 
Dessa forma, podemos identificar que a escola, por meio do currículo, detém o poder de definir qual cidadão pretende-se constituir com a formação ofertada por ela. A partir disso, diversos problemas emergem. Para explanar melhor essas dificuldades, Santos (2007, p. 293) observa as tensões curriculares no Brasil:

O que se pode observar é que há uma grande tensão quando se pensa nos currículos escolares, atualmente, no Brasil. Como modificar a educação escolar de forma a tornar a escola mais inclusiva, mais acolhedora, em relação às crianças e adolescentes das camadas populares, garantindo, ao mesmo tempo, melhor desempenho nos testes estaduais e nacionais? Abre-se mão das novas atividades, das práticas lúdicas introduzidas nas escolas? Volta-se a trabalhar com o currículo disciplinar? Como trabalhar com um currículo mais integrado, na forma de projetos, de maneira a possibilitar, ao mesmo tempo, organização e sistematização dos conteúdos estudados?

Essas perguntas parecem despertar pouco interesse em um grupo crescente de acadêmicos. As discussões sobre currículo escolar parecem, nestes últimos anos, e para algumas tendências no campo do currículo, alguma coisa fora de lugar e datada. De maneira bem direta e simples, parece que fica quase impossível, para alguns, aprofundar problemas presentes nos currículos escolares, sem ser prescritivo, e para outros, sem ser moralista, essencialista e metafísico.

Em verdade, o currículo deve ser o instrumento que estará vinculado ao Projeto Político Pedagógico (PPP), que definirá o tipo de homem a ser formado e que também evidenciará a autonomia da escola acerca dos estudantes e da realidade social e cultural da comunidade a qual a instituição está vinculada. No entanto, este trabalho encontrase em meio a impasses quando os gestores ou corpo docente, bem como as secretarias municipais e estaduais de educação, almejam um modelo de sociedade que seja contrário aos interesses da classe trabalhadora, favorecendo a manutenção do status quo da classe dominante. Com isso, fazemos uso das teorias críticas que desconfiam do estabelecido, das condições existentes, em face das injustiças sociais.

As teorias críticas desconfiam do status quo, responsabilizando-o pelas desigualdades e injustiças sociais. As teorias tradicionais eram teorias de aceitação, ajuste e adaptação. As teorias críticas são teorias de desconfiança, questionamento e transformação radical. Para as teorias críticas o importante não é desenvolver técnicas de como fazer o currículo, mas desenvolver conceitos que nos permitam compreender o que o currículo faz. (SILVA, 1999, p. 30).

Nesse sentido, fazemos uso de uma perspectiva crítico-superadora, baseada nas teorias críticas de forte influência marxista para entrar em contraposição às teorias educacionais idealistas, positivistas e reacionárias. Para isso, devemos analisar a ideologia capitalista frente à escola.

A permanência da sociedade capitalista na hegemonia se dá pela dependência da reprodução de seus componentes propriamente econômicos - meios de produção e força de trabalho - e da reprodução de seus componentes ideológicos (ALTHUSSER, 1985). Sendo assim,

Além da continuidade das condições de sua produção material, a sociedade capitalista não se sustentaria se não houvesse mecanismos e instituições encarregadas de garantir que o status quo não fosse contestado. Isso pode ser obtido através da força ou do convencimento, da repressão ou da ideologia. O primeiro mecanismo está a cargo dos aparelhos repressivos de Estado (a polícia, o judiciário); o segundo é responsabilidade dos aparelhos ideológicos de Estado (a religião, a mídia, a escola, a família). (SILVA, 1999, p. 31).

Contudo, quando voltamos para a 
realidade do ensino escolar, nos deparamos com a ideologia que leva os alunos a adquirirem conhecimentos necessários à reprodução dos componentes econômicos. As teorias do currículo estão presentes nesse processo.

Em determinado contexto histórico, o sistema educacional brasileiro lidava com teorias com o intuito de apenas conservar a burguesia como classe dominante. Contudo, vários estudiosos (Freire, 1998; Saviani, 2008; Libâneo, 1985; Coletivo de Autores, 1992; Taffarel, 1995, 2007; Castellani Filho, 1988) contribuíram confrontando teorias idealistas conservadoras, propondo um ensino preocupado em tornar a sociedade igualitária, ou seja, uma sociedade sem classes. Partindo do contraponto, analisando todo o processo de alienação dessas teorias e, assim, diagnosticando possibilidades de levar o aluno a sua emancipação por intermédio da educação escolar. Muito embora este momento ilustre uma motivação no cenário do ensino básico e superior - quando professores e pesquisadores buscam uma superação daquilo que vêm contrariando os valores humanos, que tiram usufruto da exploração do homem pelo homem, para que assim continuem expandindo suas riquezas a partir da força de trabalho alheio - são as concepções idealistas que aparecem no cenário educacional com propostas que alienam e enganam a partir de seu corpo teórico, chamando atenção das políticas formativas, bem como de inovação para a inserção deste ensino nas escolas por meio do currículo.

A escola, ao definir seu currículo, orientada por essas concepções, introduz relações sociais que expressam correspondência com as relações sociais do local de trabalho. Consoante a Silva (1999, p. 33),

[...] é, pois, através de uma correspondência entre as relações sociais da escola e as relações sociais do local de trabalho que a educação contribui para a reprodução das relações sociais da produção da sociedade capitalista.
Sendo assim, a escola estaria sendo uma representação da economia capitalista ou, mais especificamente, o local de trabalho capitalista. Para Bourdieu e Passeron (1975), a dinâmica da reprodução social está centralizada no processo de reprodução cultural. É por meio da reprodução da cultura hegemônica que a reprodução mais vasta da sociedade fica assegurada. A cultura que tem crédito e valor social é precisamente a cultura das classes hegemônicas: seus valores, seus gostos, seus costumes, seus hábitos. Na medida em que essa cultura tem apreço em termos sociais; na medida em que ela possui algum valor; na medida em que ela faz com que a pessoa que a possui obtenha proveitos materiais e simbólicos, ela se compõe enquanto capital cultural, que se encontra em vários estados. Ele pode se demonstrar em estado consubstanciado: as obras teatrais, as obras literárias, entre outras. A cultura, do mesmo modo, pode existir sob a forma de títulos e diplomas: é o capital cultural institucionalizado. Impreterivelmente, ele mostra-se de forma congregada e internalizada. Nesse último arranjo, ele se atordoa com o habitus.

O currículo da escola está baseado na cultura dominante: ele se expressa na linguagem dominante, ele é transmitido do código cultural dominante. As crianças das classes dominantes podem facilmente compreender esse código, pois durante toda sua vida elas estiveram imersas, o tempo todo, nesse código. Esse código é natural para elas. Elas se sentem a vontade no clima cultural e afetivo construído por esse código. É o seu ambiente nativo. Em contraste, para as crianças e jovens das classes dominadas, esse código é simplesmente indecifrável. Eles não sabem do que se trata. Esse código funciona como uma linguagem estrangeira: é incompreensível. (SILVA, 1999, p. 35).

Esta concepção reflete bem a influência da hegemonia burguesa no sistema de ensino escolar. O modelo exposto toma forma quando 
as teorias idealistas e reacionárias permeiam o âmbito do currículo escolar. Portanto, identificamos, no horizonte histórico com a decomposição das forças produtivas, a miséria em todos os territórios do globo. Inserido nesse quadro, Dantas Júnior e Taffarel (2007, p. 406) destacam que

[...] a última década do século 20 gerou no seio da intelectualidade uma interpretação/solução simples: nada mais se explica historicamente. O fim do século 20 foi a "era do fim": da História, do projeto iluminista, das ideologias, da racionalidade científica. Propugna-se, então, a explicação pelo "sentido" e pela "interpretação", descortinando o alvorecer de algo ainda não fixado nominalmente: pós-modernidade, supermodernidade ou hipermodernidade.

Não se pode descartar o papel do materialismo histórico. Se considerássemos o triunfo do capitalismo, seria necessário, sobretudo, criticar o vigente sistema, para que pudéssemos refleti-lo e compreendêlo criticamente para sua caracterização e superação. Faz-se necessário o uso de um pensamento crítico frente aos problemas sociais impostos pelo modo de produção capitalista, ou seja, a perspectiva crítica de superação de mazelas sociais torna-se essencial para o currículo escolar. Com isso, são necessárias pesquisas para obter uma posição teórica para a reconceitualização do currículo, tendo a história como horizonte e diálogo teórico-prático para introdução e ação no mundo material que se concretiza no trabalho pedagógico, sendo na escola ou para além dela, em especial os campos de atuação profissional de Educação Física (DANTAS JUNIOR; TAFFAREL, 2007). As concepções críticas de educação devem estar presentes no currículo da Educação Física na escola. A partir disso, uma metodologia plausível é imprescindível para o exercício dessas perspectivas críticas. A partir do Coletivo de Autores (1992), a perspectiva crítico-superadora aqui é compreendida como um dos tipos de apreensão do conhecimento característico da Educação Física, tratado com base em uma visão de totalidade, onde sempre está presente o específico de cada tema da cultura corporal e a abrangência, que é a expressão do corpo como linguagem social e historicamente construída.

Essa perspectiva visa denunciar os modelos reprodutores do sistema que mantém a estrutura social de forma injusta e que reforça as relações de dominação de um grupo sobre outro. A pedagogia crítica defende uma proposta de conteúdos do ponto de vista da classe trabalhadora. Propaga que a relação educação-sociedade é influenciada dialeticamente, isto é, a escola é influenciada pela sociedade e esta também pode ser influenciada pela escola. Nesta perspectiva, a tarefa dos educadores críticos não é a transformação social via escolarização, mas oferecer a democratização dos saberes universais e fazer compreender o papel que as escolas representam dentro de uma sociedade marcada por relações de poder. (NUNES; RÚBIO, 2008, p. 71).

Sendo assim, o currículo, o qual podemos determiná-lo como sendo as experiências pedagógicas do aluno durante todo o percurso/processo de apreensão do conhecimento científico historicamente construído pelo homem, por meio da prática social e que a escola seleciona, é capaz:

[...] de dar conta de uma reflexão pedagógica ampliada e comprometida com os interesses das camadas populares tem como eixo a constatação, a interpretação, a compreensão e a explicação da realidade social complexa e contraditória. Isso vai exigir uma organização curricular em outros moldes, de forma a desenvolver uma outra lógica sobre a realidade, a lógica dialética, com a qual o aluno seja capaz de fazer uma outra leitura. Nesta outra forma de organização curricular se questiona o objeto de cada disciplina ou matéria curricular e coloca-se em destaque a função social de cada uma delas no 
currículo Busca situar a sua contribuição particular para explicação da realidade social e natural no nível do pensamento/reflexão do aluno. Isso porque o conhecimento matemático, geográfico, artístico, histórico, lingüístico, biológico ou corporal expressa particularmente uma determinada dimensão da "realidade" e não a sua totalidade. (COLETIVO DE AUTORES, 1992, p. 17).

Por fim, a função social do currículo é estabelecer a reflexão pedagógica do aluno de forma a pensar a realidade social, ampliando uma lógica determinada. Para isso, apropriase do conhecimento científico, contrapondo-o ao que o aluno traz do seu meio social cotidiano e de outras relações do pensamento humano: as atividades, as relações culturais, as relações sociais, a ideologia entre outras.

\section{Proposições para uma Educação Física além do conservadorismo}

A educação sofre influências de poderes, os quais constituem o país "executivo, legislativo e judiciário", três pilares que movimentam os sistemas voltados para a sociedade, ou seja, um processo hierárquico que ocorre com influências advindas de cima para baixo. Com isso, destacamos o estudo de Althusser (1970) que evidencia a escola como sendo um aparelho ideológico do Estado, sua função de reprodução social, bem como a escola como principal veículo para a alienação a partir do currículo reacionário, que determinará a perpetuação social dos estudantes das camadas populares.

Para Bourdieu (1999, p. 41), o sistema escolar

é um dos fatores mais eficazes de conservação social, pois fornece a aparência de legitimidade às desigualdades sociais, e sanciona a herança cultural e o dom social tratado como dom natural.

Portanto, a herança cultural é a premissa inicial responsável pela divergência da criança na escola, pois cada família remete a seus filhos determinado capital cultural e determinado sistema de valores que contribuem para definir suas atitudes diante do capital cultural e da instituição escolar. No âmbito escolar, a Educação Física está diante de alguns impasses, que se caracterizam por estarem centrados no campo teórico, quando ainda falta consonância nos diversos assuntos das ciências da saúde, humanas e sociais. A falta de investimento estrutural acarreta a precarização do componente curricular, não obtendo recursos materiais para a execução de suas aulas. Além disso, influencia na identidade do professor de Educação Física, que, por sua vez, quando defende uma identidade técnica, suas aulas não estão voltadas para a formação humana, tampouco para a transformação social, mas em valorizar a aquisição das habilidades específicas que resultem em equipes esportivas fortes, capazes de adquirem resultados positivos em competições escolares. Ou seja, a Educação Física torna-se uma disciplina conservadora na vida escolar daquele aluno. Conforme a Carta de Carpina, do Coletivo de Autores (2001, p. 35)

Numa perspectiva tecnicista, a busca do campeão desencadeia um processo seletivo e discriminatório sobre as crianças, e os que a ele sobrevivem são chamados de "talentos". Talentos para o quê? Seguramente para suportar os castigos que a injustiça social impõe e ainda pendurar no pescoço a medalha que o país, o professor, o técnico, o dirigente, o governador, o presidente tanto anseiam. Não basta recusar essa Educação Física; é necessário compreender as causas dessa miséria pedagógica que, no ambiente escolar, marginaliza os cidadãos deste país. Nesta nefasta ação pedagógica, igualam-se a Educação Física a matemática, a geografia, a história e outras. Os professores de Educação Física, através da história, ainda não conseguiram encontrar, em sua ação teórico-prática, dimensão social que justifique a existência da Educação Física, ou seja, esta 
não tem dado conta de dimensionar sua prática no sentido de explicitar e entender as contradições e conflitos inerentes à educação.

A partir disso, podemos destacar a necessidade da apreensão da Educação Física, no que diz respeito aos conflitos da Educação, enquanto a instituição escolar enfatiza conservar as classes sociais na sociedade. Diante disso, a escola assume uma finalidade objetiva: conservar os valores que justificam a ordem social dominante. Contra essa prática cultural se rebelaria

[...] uma pedagogia racional e universal, que, partindo do zero e não considerando como dado o que apenas alguns herdaram, se obrigaria a tudo a favor de todos e se organizaria metodicamente em referência ao fim explícito de dar a todos os meios de adquirir aquilo que não é dado, sob a aparência de dom natural, senão às crianças das classes privilegiadas. (BOURDIEU, 1999, p. 53).

Neste sentido, a metodologia utilizada é uma que não se encaixa com as metodologias e abordagens reacionárias, mas uma que:

[...] implica um processo que acentue, na dinâmica da sala de aula, a intenção prática do aluno para apreender a realidade. Por isso, entendemos a aula como um espaço intencionalmente organizado para possibilitar a direção da apreensão, pelo aluno, do conhecimento específico da Educação Física e dos diversos aspectos das suas práticas na realidade social. (COLETIVO DE AUTORES, 1992, p. 62).

Isto oportunizaria aos estudantes elencarem suas experiências socioculturais, no que diz respeito à vivência de seu dia-a-dia, colocando-a na aula, junto com o saber do professor. Assim, possibilitaria a materialização de atividades de caráter crítico e dialético.

A grande questão é: os professores de Educação Física estariam deixando de lado a realidade social dos estudantes que sua escola acolhe para apenas ministrarem aulas voltadas para o ensino das técnicas apuradas em poucos elementos da cultura corporal? Esta abordagem do professor estaria contribuindo na formação crítica do aluno? Qual a intervenção correta a ser tomada diante de determinados problemas educacionais?

$\mathrm{Na}$ verdade, o que podemos levar em consideração, é a existência de concepções idealistasnomeioescolar, bemcomo, concepções alienadoras que permeiam as escolas públicas. A Educação Física, como disciplina curricular, deve promover a formação humana do educando no que diz respeito à constituição de uma identidade para que possa atuar na sociedade de modo que venha a refletir criticamente sobre as injustiças sociais, podendo transformar todo o sistema social de desigualdade ${ }^{10}$. Então, faz-se propício explanar, brevemente, os princípios da perspectiva adotada para o trabalho acerca da formação humana. Essa perspectiva movimenta-se ao encontro das disposições populares manifestadas historicamente por meio de resoluta metodologia de ensino da Educação Física, qual seja a metodologia crítico-cuperadora (COLETIVO DE AUTORES, 1992).

Diante da crítica social, tal perspectiva viabiliza a formação/constituição de sujeitos autônomos, críticos, cientes de sua condição histórica e que se percebam, enquanto mediadores, na formação de sua própria realidade. Essa perspectiva da Educação Física levanta como objeto de trato da reflexão pedagógica o saber de uma área designada Cultura Corporal, caracterizada com temas ou tipos de atividades corporais, como o esporte,

10. Refletindo sobre a formação humana, iniciando desde a educação, por um processo da ação pedagógica, tendo como pontapé inicial a ação social, com a constituição de identidades advindas desse processo, as grandes massas estariam preparadas para lutarem por uma sociedade igualitária, pois estas estariam instrumentalizados com um lastro teórico e político. 
o jogo, a dança, a ginástica e a capoeira, que irão compor seu conteúdo. Nesse sentido, é intuitivo promover, por meio do trato com os conhecimentos concebidos pela Cultura Corporal, um questionamento da realidade que seja apto a "responder determinados interesses de classe" e que, por intermédio da construção da crítica social, persista na procura da emancipação das camadas populares, ou seja, das classes oprimidas (COLETIVO DE AUTORES, 1992, p. 25).

O desenvolvimento de uma percepção de historicidade da Cultura Corporal tem imprescindível relevância para essa perspectiva, uma vez que o conhecimento deve ser ajustado de maneira a traçar desde sua gênese e cerne, oportunizando aos educandos determinada visão, concedendo-lhes compreender-se enquanto sujeitos sócio-históricos.

O que vai permitir a efetivação deste trabalho são os conteúdos a serem abordados nas aulas de Educação Física, mediados pela perspectiva crítico-superadora. Esses conteúdos deverão apresentar uma pertinência social a ser trabalhada que trate o conhecimento de modo que tenha um sentido junto a determinada realidade social e que, por meio dele, possamos refletir sobre situações existentes na sociedade, na região, na escola, e nos identificar nessa temática (ALVES, 2006).

Esta relevância social dos conteúdos consiste em:

Compreender o sentido e o significado do conteúdo para a reflexão pedagógica escolar [...] deverá estar vinculado à explicação da realidade social concreta e oferecer subsídios para a compreensão dos determinantes sóciohistóricos do aluno, particularmente a sua condição de classe social. (COLETIVO DE AUTORES, 1992, p. 31).

A mediação dos conteúdos da Educação Física, a partir da perspectiva crítico-superadora, exerce uma transição para esta área do conhecimento, ouseja, deixadeladoavalorização do tecnicismo e rendimento esportivo e passa a valorizar a formação humana dos educandos, bem como a formação integral da comunidade estudantil. Esta tendência na formação crítica e autônoma dos educandos estará contribuindo para a construção de um modelo de sociedade emancipada, igualitária, isonômica e sem classes.

\section{Concepções metodológicas para o ensino da Educação Física na perspectiva da formação humana}

Partindo do pressuposto da formação humana, torna-se necessário buscarmos, a partir da ontologia, os processos da formação do ser social, procurando contribuir, por meio do ensino da Educação Física, na formação humana dos educandos. Para que este feito seja possível, elaboraremos procedimentos pedagógicos que façam unidade entre teoria e práxis (prática social) dentro de sua prática educativa.

O homem, ao longo de sua história, teve o trabalho como elemento fundamental para o seu desenvolvimento, pois este é o fundamento ontológico do ser social.

É através do trabalho, mediação necessária entre homem e natureza, que o homem se destaca da esfera natural e instaura um novo plano ontológico, que se caracteriza por níveis crescentes de socialização. (COSTA, 2009, p. $4)$.

É, por meio do trabalho, que o homem transforma a natureza e se transforma, um processo de reciprocidade.

No processo do trabalho a produção de um objeto não é uma simples modificação da realidade, pois cada objetivação em seu processo de efetivação transforma, além da materialidade natural, o próprio sujeito que conduz a transformação, o qual adquirindo novas habilidades e conhecimentos se exterioriza como sujeito. Portanto, a partir de cada ato de trabalho que produz uma 
objetivação-exteriorização, surge uma nova situação tanto no aspecto objetivo como no aspecto subjetivo. (COSTA, 2009, p. 4).

Nesse sentido, no aspecto objetivo que se refere ao mundo dos homens, é introduzido um objeto antes inexistente, incorporado no contexto social já existente, propiciando novas possibilidades, desconhecidas para os seus criadores. Essas possibilidades estão enquanto resultado do fato do novo condicionar e ser condicionado pela totalidade concreta. Por outro lado, o aspecto subjetivo refere-se à própria consciência que se encontra mais engrandecida por novos conhecimentos e habilidades, inconcebíveis antes do ato do trabalho, o que fomenta o indivíduo, pelo próprio trato social, a generalizar suas novas aptidões.

Assim, foram se formando, por meio do acúmulo constante de conhecimentos parciais, objetivações universais, como a ciência, a tecnologia e a filosofia. Essa ação alarga-se com a maior complexidade das relações, intercâmbios sociais e associação das comunidades humanas, o que torna mais evidenciado e desenvolvido o complexo social da educação.

O senso de humanidade no homem é produzido por meio da objetivação da natureza e do trabalho, que se integra como tal, precisamente, pela apropriação desse patrimônio - espiritual e material - resultante do trabalho e que foi acumulado ao longo da história. Sobre a assimilação dos fenômenos e objetos que estabelecem a realidade, Leontiev (1978, p. 286) diagnostica que "[...] é necessário desenvolver em relação a eles uma atividade que reproduza, pela sua forma, os traços essenciais da atividade acumulada no objeto".

A educação detém uma função imprescindível na formação do ser dos homens. Leontiev (1978) usa um exemplo que permite perceber a função mediadora da educação com as outras dimensões sociais, bem como sua especificidade na reprodução do ser social, por meio do procedimento de apropriação e transmissão da cultura do gênero humano aos indivíduos:

Se nosso planeta fosse vítima de uma catástrofe que só pouparia as crianças mais pequenas e na qual pereceria toda a população adulta, isso não significaria o fim do gênero humano, mas a história seria inevitavelmente interrompida. Os tesouros da cultura continuariam a existir fisicamente, mas não existiria ninguém capaz de revelar às novas gerações o seu uso. As máquinas deixariam de funcionar, os livros ficariam sem leitores, as obras de arte perderiam a sua função estética. A história da humanidade teria que recomeçar. O movimento da história só é, portanto possível com a transmissão, às novas gerações, das aquisições da cultura humana, isto é, com educação. (LEONTIEV, 1978, p. 272-273).

Com isso, buscamos propiciar o exercício da prática educativa do ensino da Educação Física, voltado para a reflexão da cultura corporal, fomentando o professor a eleger, para sua prática, uma perspectiva que responda às exigências atuais do procedimento de construção da qualidade da escola, procurando, assim, desenvolver uma reflexão pedagógica por meio da transmissão dos conteúdos da cultura corporal sobre o acúmulo de formas de representação do mundo que o homem tem produzido no transcorrer da história, exteriorizadas pela expressão corporal: danças, lutas, jogos, ginástica, esporte, artes circenses e outros, que podem ser identificados como meios de representação simbólica de realidades vivenciadas pelo homem, criadas historicamente e desenvolvidas culturalmente (COLETIVO DE AUTORES, 1992).

Para a efetivação da perspectiva críticosuperadora, partimos de algumas características específicas da reflexão pedagógica: é diagnóstica, judicativa e teleológica (SOUZA, 1987). Diagnóstica, porque expõe o reconhecimento e leitura dos dados da realidade; judicativa, 
pois avalia com início em uma ética que representa os anseios de determinada classe; e teleológica, por definir um ponto onde se pretende chegar, procura direção. Para isso, é preciso que cada professor de Educação Física tenha definido: qual o projeto de sociedade e de homem que se busca formar? Quais são os interesses de classe preserva? Nesse sentido, a partir do trato com o conhecimento, pode-se refletir o caminho epistemológico que informa as condições para selecionar, organizar e sistematizar os conteúdos a serem transmitidos.

Osconteúdosdaculturacorporalirãopassar por seleção. Portanto, remeterão à necessidade de organizá-los e sistematizá-los, tendo como base alguns princípios metodológicos, atrelados à forma como serão tratados no currículo, bem como a lógica com que serão proporcionados aos alunos. Primeiramente, ressalta-se o princípio da confrontação e da contraposição de saberes, isto é, serão compartilhados significados estabelecidos no pensamento do aluno por meio de referências distintas: o conhecimento científico ou saber escolar é o saber edificado como resposta às requisições do seu meio cultural informado pelo senso comum (COLETIVO DE AUTORES, 1992).

O saber popular que o aluno traz, advindo de sua vivência e de suas relações sociais, será confrontado com o conhecimento científico, selecionado pela instituição de ensino. Do ponto de vista metodológico, o saber desta instituição é imprescindível para a reflexão pedagógica, porque fomenta o estudante, ao decorrer de sua escolarização, a superar o senso comum e a materializar modos mais elaborados de pensamento. Para Libâneo (1985, p. 40), não se trata de

oposição entre cultura erudita e cultura popular ou espontânea, mas uma relação de continuidade em que, progressivamente, se passa da experiência imediata ao conhecimento sistematizado.
Na perspectiva dialética, os conteúdos teriam que ser proporcionados aos alunos a partir do princípio da simultaneidade, tornando explícita a relação que sustentam entre si para desenvolver a compreensão de que são dados da realidade concreta e que não podem ser pensados nem explicitados de forma isolada. Nessa perspectiva, o que modificaria de uma unidade para outra seria a amplitude das referências sobre cada dado, isso porque "o conhecimento não é pensado por etapas. Ele é construído no pensamento de forma espiralada e vai se ampliando" (VARJAL, 1986, p. 35).

Sendo assim, estaríamos possibilitando uma prática educativa que tivesse a prática social como ponto de partida e de chegada, porque o homem é um ser determinado historicamente e socialmente. Assim, esta proposta de ensino possibilitaria uma prática transformadora, viabilizando a formação omnilateral, no que diz respeito não à especialização precoce, mas que possibilite aoaluno se apropriar doacervocultural acumulado para sua formação humana. Assim, o estudante possuirá condições de constatar, interpretar e compreender a realidade social.

\section{Considerações Finais}

Passamos por processos de firmação de conhecimentos e de impasses, enfrentados frente à opressão advinda dos interesses das classes dominantes. Todavia, o enfraquecimento das forças produtivas que advém dos interesses hegemônicos serve para alienar e aumentar ainda mais a exploração do homem pelo homem. Portanto, torna-se imprescindível uma intervenção pedagógica libertadora, que seja introduzida nesta realidade, em especial no âmbito escolar.

Para que possamos superar as mazelas causadas pelo modo de produção capitalista e pela opressão da classe dominante, é necessário refletir e intervir nas escolas de formação de professores, em especial os de 
Educação Física, que se encontram diante de DCNs e Sistema CONFEF/CREF que, por meio de suas normativas, precarizam e alienam o trabalho docente destes profissionais. Devemos superar as contradições do currículo, sabendo, acima de tudo, quais conteúdos promovem intervenção significativa na sociedade, a ponto de formar o cidadão para realizar reflexões críticas acerca da exploração capitalista. Nesse sentido, consideramos a perspectiva crítica da Educação Física como ponto de partida para o trabalho de conscientização libertadora dos alunos, propondo como eixo norteador do exercício da docência a unidade teoria-prática, uma práxis que vincule os conhecimentos científicos e individuais da cultura corporal; que considere o aluno como ser sócio-histórico; e que o ajude no processo de emancipação, tornando-o capaz de intervir na realidade e buscar a superação dessa sociedade de classes.

\section{Referências}

ALTHUSSER, L. Aparelhos ideológicos de Estado: nota sobre os aparelhos ideológicos de estado. 3 ed. Rio de Janeiro: Graal, 1985.

ALTHUSSER, L. Ideologia e aparelhos ideológicos de Estado. Lisboa: Presença, 1970.

ALVES, M. S. Educação física e formação humana: uma reflexão a partir da prática de ensino e da vivência com a metodologia crítico-superadora. Motrivivência, Florianópolis, v. 26, p. 127-138, 2006.

BOURDIEU, P. Escritos de educação. Petrópolis: Vozes, 1999.

BOURDIEU, P.; PASSERON, J. A reprodução. Rio de Janeiro: Francisco Alves, 1975.

CASTELLANI FILHO, L. Educação física no Brasil: a história que não se conta. Campinas: Papirus, 1988.

COLETIVO DE AUTORES. A carta de carpina educação física - novos compromissos: pedagogia, movimento, miséria. Revista Brasileira de Ciências do Esporte, Campinas-SP, v. 23, n.1, p. 33-40, set. 2001.

COLETIVO DE AUTORES. Metodologia do ensino de educação física. São Paulo: Cortez, 1992.

COSTA, F. Trabalho, reprodução social e educação a partir da ontologia do ser social. Trabalho Necessário, Niterói, ano 7, v. 9, p. 1-15, 2009.

DANTAS JUNIOR, H. S.; TAFFAREL, C. N. Z. Formação de professores de educação física: a história como matriz científica. In: TAFFAREL, C. N. Z.; HILDEBRANDT-STAMANN, R. (Org.). Currículo e educação física: formação de professores e prática pedagógica nas escolas. Ijuí: Editora Unijuí, 2007.

LÊNIN. V. I. Imperialismo, fase superior do capitalismo. Apresentação de Plínio de Arruda Sampaio Júnior. Campinas-SP: Editora da UNICAMP, 2011. 
LEONTIEV, A. O desenvolvimento do psiquismo. Lisboa, Portugal: Livro Horizonte, 1978.

LIBÂNEO, J. C. Democratização da escola pública: a pedagogia crítico-social dos conteúdos. São Paulo: Loyola, 1985.

MARX, K; ENGELS, F. Manifesto comunista. São Paulo: Boitempo, 2007.

MÉSZÁROS, I. A educação para além do capital. 2. ed. São Paulo: Boitempo, 2008.

NUNES, M. L. F.; RUBIO, K. O(s) currículo(s) da educação física e a constituição da identidade de seus sujeitos. Currículo sem Fronteiras, v. 8, n. 2, p. 55-77, jul.-dez. 2008.

SANTOS, L. L. C. P. Currículo em tempos difíceis. Educação em Revista, Belo Horizonte, v. 45, p. 291-306, jan.-jun. 2007.

SAVIANI, D. Escola e democracia. 40. ed. Campinas, SP: Autores Associados, 2008.

SAVIANI, D. Formação de professores: aspectos históricos e teóricos do problema no contexto brasileiro. Revista Brasileira de Educação, v. 14, n. 40, p. 143-155, 2009.

SAVIANI, D. História das ideias pedagógicas no Brasil. 3. ed. Campinas, SP: Autores Associados, 2010.

SAVIANI, D. Pedagogia histórico-crítica: primeiras aproximações. 6. ed. Campinas: Autores Associados, 1997. (Coleção Polêmicas do Nosso Tempo).

SAVIANI, D.; DUARTE, N. Pedagogia histórico-crítica e luta de classes na educação escolar. Campinas, SP: Autores Associados, 2012.

SILVA, T. T. Documentos de identidade: uma introdução às teorias do currículo. Belo Horizonte: Autêntica, 1999.

SILVA JÚNIOR, J. dos R. Pragmatismo e populismo na educação superior nos governos FHC e Lula. São Paulo: Xamã, 2005.

SOUZA, J. F. de. Uma pedagogia da revolução. São Paulo: Cortez: Autores Associados, 1987.

TAFFAREL, C. N. Z. et al. Formação de professores de educação física para a cidade e o campo. Pensar a Prática, Goiânia, v. 9, n. 2, p. 153-179, 2006.

TAFFAREL, C. N. Z. et al. Uma proposição de diretrizes curriculares para a formação de professores de educação física. In: TAFFAREL, C. N. Z.; HILDEBRANDT-STRAMANN, R. (Org.). Currículo e educação física: formação de professores e prática pedagógica nas escolas. Ijuí: Editora Unijuí, 2007.

TAFFAREL, C. N. Z.; SANTOS JÚNIOR, C. L. Formação humana e formação de professores de educação física: para além da falsa dicotomia licenciatura versus bacharelado. In: TERRA, D. V.; SOUZA JÚNIOR, M. (Org.). Formação em educação física \& ciências do esporte: políticas e cotidiano. São Paulo: Aderaldo \& Rothschild; Goiânia: CBCE, 2010. 
VARJAL, E. Para além da grade curricular. Revista Educação e Debate, Recife, Ano 1, n. 1, 1986.

WOOD, E. M. O que é a agente "pós-moderna"? In: WOOD, E. M.; FOSTER, J. B. (Org.). Em defesa a história: marxismo e pós-modernismo. Rio de Janeiro: J. Zahar, 1999.

Submetido em 16 de maio de 2013.

Aprovado em 19 de junho de 2013. 